\title{
Investigation of replacement fluids and retention-interval effects in taste-aversion learning
}

\author{
W. ROBERT BATSELL, JR., and MICHAEL R. BEST \\ Southern Methodist University, Dallas, Texas
}

\begin{abstract}
In two experiments, taste aversions were tested at different retention intervals. Experiment 1 demonstrated that saccharin aversions were significantly weaker when tested 1 day following conditioning than when tested 3,5 , or 10 days after conditioning. It was hypothesized that the increased drinking observed at the 1-day testing interval might be attributable to limited fluid exposure during the conditioning-to-testing interval (CTI). The results of Experiment 2 indicated that providing replacement fluids during the CTI did not eliminate these retention-interval differences. Instead, these results suggested that an alternative associative or nonassociative mechanism was responsible for the retention-interval effect.
\end{abstract}

Conditioned taste aversions are known for their robustness in part because they persist over retention intervals as long of 90 days (Dragoin, Hughes, Devine, \& Bentley, 1973). Although they are known for their strength, both single-element and compound-element taste aversions are significantly weaker if they are tested 1 day after conditioning than if they are tested at longer retention intervals (e.g., Batsell \& Best, 1992a, 1992b; Biederman, Milgram, Heighington, Stockman, \& O'Neill, 1974; Kraemer, Lariviere, \& Spear, 1988; Miller, Jagielo, \& Spear, 1990). For example, Batsell and Best (1992b) reported that saccharin aversions tested at a 1-day retention interval are weaker than those tested either 6 days or 21 days after conditioning. Similarly, Biederman et al. (1974) tested saccharin aversions $90 \mathrm{~min}, 1$ day, 2 days, 3 days, 7 days, 10 days, and 14 days after conditioning; however, they reported that aversion strength resembled an inverted U-shaped function, with stronger aversions at the shortest and longest retention intervals. Considering the lack of agreement in these studies, a reexamination of the pattern of developing aversion strength is warranted. Experiment 1 was designed to examine the time course of developing aversion strength. Specifically, aversions were tested 1, 3, 5 and 10 days after conditioning. Animals were not tested at the 90 -min interval because these results are likely confounded with continued illness.

\section{EXPERIMENT 1}

\section{Method}

Subjects and Apparatus. Thirty-two white male Holtzman rats, ranging between 250 and $450 \mathrm{~g}$, served as subjects. All rats were housed

The current research was supported by NSF Grant BNS-8809508. The authors are indebted to Howard Hurd and Chris Jones for their help conducting these studies. Reprints are available from Robert Batsell, Department of Psychology, Southern Methodist University, Dallas, TX 75275. singly in standard Wahmann hanging cages in a vivarium on a $12: 12$-h light:dark cycle. All manipulations were conducted in these familiar home cages. The animals had ad-lib access to Purina Rat Chow throughout the experiment, and they were kept on water deprivation for 2 weeks prior to conditioning. During this water-deprivation regimen, the rats were given 20 -min access to $40 \mathrm{ml}$ of room-temperature tap water at $1100 \mathrm{~h}$. All fluids were presented in 50-ml calibrated polypropylene centrifuge tubes fitted with rubber stoppers, and the intakes were recorded to the nearest $0.1 \mathrm{ml}$. The taste stimulus used in this experiment was a $1.5 \%$ sodium saccharin solution. An $0.15-\mathrm{M}$ lithium chloride solution (LiCl; $12 \mathrm{mg} / \mathrm{kg}$ of body weight) was injected intraperitoneally (i.p.) to induce toxicosis.

Procedure. The animals were placed into four groups $(n=8)$ on the basis of their mean water intake for a 10-day period prior to conditioning. The four groups were differentiated by their conditioning-to-testing intervals (CTIs): 1 day (Group R1), 3 days (Group R3), 5 days (Group R5), and 10 days (Group R10). Conditioning occurred on different days, and all groups were tested together. At a given conditioning interval, a group of rats was presented with $8 \mathrm{ml}$ of saccharin for $10 \mathrm{~min}$. Fifteen minutes later, these animals were aversively conditioned. No replacement fluids were presented to these animals until $24 \mathrm{~h}$ following conditioning. During this procedure, all other groups received their daily water maintenance. This procedure was used at each of the conditioning intervals except the 1-day interval. To equate thirst levels prior to testing, all groups received $8 \mathrm{ml}$ of fluid for $10 \mathrm{~min}$ at the 1-day conditioning interval. Group $R 1$ received $8 \mathrm{ml}$ of saccharin, and the other groups received $8 \mathrm{ml}$ of water.

For testing, the rats were given $20-\mathrm{min}$ access to $30 \mathrm{ml}$ of saccharin in their home cages. This testing procedure was repeated on the next day. A one-bottle testing method was used because this procedure is more effective than a two-bottle method in detecting retention-interval differences (Batsell \& Best, 1992a). Also, $5 \mathrm{~h}$ after testing, all animals received their normal water maintenance $(40 \mathrm{ml}$ of water for $20 \mathrm{~min})$.

\section{Results and Discussion}

The animals were matched to groups according to their water-deprivation intakes prior to conditioning. Group means ranged from 20.4 to $20.5 \mathrm{ml}$. During conditioning, all groups drank equal amounts of saccharin: Group R1 = $4.3 \mathrm{ml}$, Group R3 $=4.6 \mathrm{ml}$, Group R5 $=4.4 \mathrm{ml}$, and Group R10 = $4.4 \mathrm{ml}$.

Figure 1 displays the groups' mean saccharin intake averaged over Test Days 1 and 2. On Test Day 1, Group 


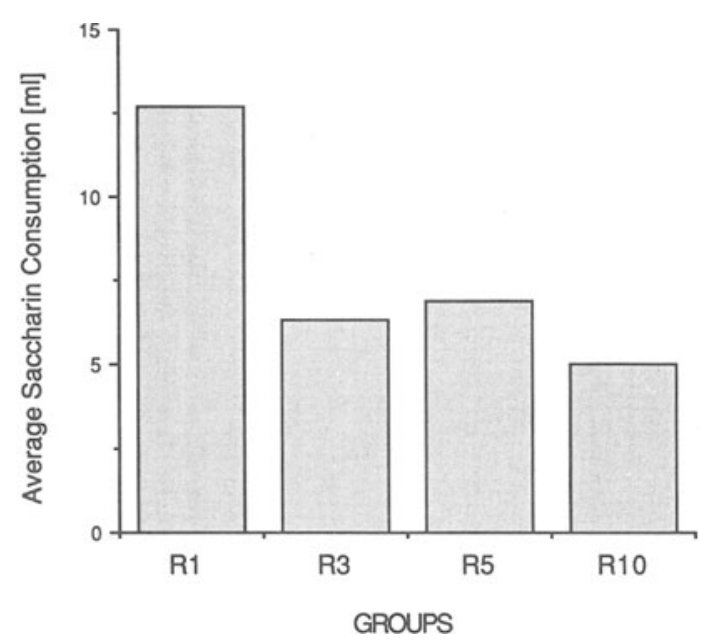

Figure 1. Mean saccharin intake in millimeters averaged over Test Days 1 and 2 of groups tested 1 day (R1), 3 days (R3), 5 days (R5), or 10 days (R10) after conditioning.

$R 1$ readily consumed saccharin, whereas the other groups avoided it. Group means were Group R1 $=6.2 \mathrm{ml}$, Group R3 = $2.1 \mathrm{ml}$, Group R5 = $3.2 \mathrm{ml}$, and Group $\mathrm{R} 10=2.1 \mathrm{ml}$. On Test Day 2, this pattern of responding continued as Group R1 drank substantially more than did the other groups. Group means were Group R1 = $19.3 \mathrm{ml}$, Group R3 = $10.6 \mathrm{ml}$, Group R5 $=10.8 \mathrm{ml}$, and Group R10 = $7.9 \mathrm{ml}$. The $4 \times 2$ analysis of variance (ANOVA) revealed a significant group effect $[F(3,28)=5.8, p<.01]$. Specific planned comparisons confirmed that Group R1 drank significantly more saccharin than did the other groups $(p<.01)$, whereas the other groups did not differ significantly. Also, the trials effect $[F(1,28)=113.6, p<.01]$ and the trials $\times$ group interaction $[F(3,28)=3.7, p<.05]$ were significant. These results indicate that the animals tested 1 day after conditioning demonstrated a more rapid rate of extinction than did those tested at longer retention intervals (cf. Batsell \& Best, 1992b).

In Experiment 1, the rats aversively conditioned to saccharin and tested $24 \mathrm{~h}$ later drank significantly more saccharin than did comparably conditioned animals tested at longer retention intervals $(3,6$ or 10 days). These results replicate earlier findings that taste aversions tested $24 \mathrm{~h}$ after conditioning are significantly weaker than those tested at longer retention intervals (i.e., 6 or 21 days; Batsell \& Best, 1992b). Furthermore, the present outcome extends previous research by suggesting that taste aversions tested within 3 days of conditioning are not subject to the decrements observed at the 1-day interval.

In those earlier studies, Batsell and Best (1992b) demonstrated that the retention-interval differences were not due to factors such as the aftereffects of illness or differential hydration. However, the absence of fluid exposure following conditioning may be responsible for the increased drinking at $24 \mathrm{~h}$. For instance, in Experiment 1, the animals tested 3 days after conditioning had the op- portunity to consume water during the CTI, whereas the 1-day group did not receive any replacement fluids during this interval. It is possible that the absence of replacement fluids coupled with the limited fluid intakes contributed to the retention-interval differences. This possibility was investigated in Experiment 2.

\section{EXPERIMENT 2}

Although the results of Experiment 1 strongly suggest that a saccharin aversion increases in strength for a 72-h period following conditioning, this effect was confounded with the absence of replacement fluids during the CTI. To evaluate the contribution of replacement fluids during this interval, four groups of rats were tested. Two groups of rats were aversively conditioned to saccharin with a 5-day retention interval, and the other two groups were conditioned with a 1-day interval. All animals were conditioned in a similar manner; however, one group at each retention interval was given $10 \mathrm{ml}$ of water before testing, and the other group was not.

\section{Method}

Thirty-five male Holtzman rats were subjects in this experiment. The animals weighed between 270 and $420 \mathrm{~g}$ at conditioning. All experimental conditions were the same as previously reported. The animals were matched into four groups prior to conditioning. Groups were designated by their retention interval ( 1 or 5 days) and by whether they received replacement fluids following conditioning: water $(W)$ or no water $(N)$. Thus, the groups were $1 \mathrm{~W}(n=9), 1 \mathrm{~N}(n=9), 5 \mathrm{~W}(n=9)$, and $5 \mathrm{~N}(n=8)$.

The conditioning procedure was the same in Experiment 1 except Groups $5 \mathrm{~W}$ and $1 \mathrm{~W}$ received 10 -min access to $10 \mathrm{ml}$ of tap water $5 \mathrm{~h}$ after conditioning. To equate fluid experience, these groups received this fluid after both 5-day and 1-day conditioning. As such, Groups 5W and $1 \mathrm{~W}$ should not differ in relative hydration on Test Day 1. Following 1-day conditioning, Groups $5 \mathrm{~N}$ and $1 \mathrm{~N}$ did not receive any replacement fluids until $24 \mathrm{~h}$ later (i.e., testing). Testing was the same as in the previous experiment. Because the effects of this watering manipulation would be most pronounced at Test Day 1 , only 1 day of testing was conducted and analyzed.

A $2 \times 2$ ANOVA was performed using retention interval ( 1 vs. 5 days) and hydration (water vs. no water) as factors. It should be noted that comparisons were not made between Group $5 \mathrm{~W}$ and $5 \mathrm{~N}$ or between Groups $1 \mathrm{~N}$ and $1 \mathrm{~W}$ since any differences are confounded by both differential hydration and the opportunity of replacement fluids.

\section{Results and Discussion}

The animals were matched to groups on the basis of their mean water intake for the 2 weeks before conditioning. All groups drank $21.8 \mathrm{ml}$. Also, group differences were not observed in saccharin consumption at conditioning. The group means were Group $5 \mathrm{~W}=5.9 \mathrm{ml}$, Group $5 \mathrm{~N}=$ $6.3 \mathrm{ml}$, Group $1 \mathrm{~W}=6.4 \mathrm{ml}$, and Group $1 \mathrm{~N}=6.4 \mathrm{ml}$.

Figure 2 presents the mean saccharin intake on Test Day 1. Both 5-day groups drank substantially less saccharin than did the comparably conditioned 1-day groups. The group means were Group $1 \mathrm{~N}=7.9 \mathrm{ml}$, Group $1 \mathrm{~W}=5.1 \mathrm{ml}$, Group $5 \mathrm{~N}=2.2 \mathrm{ml}$, and Group $5 \mathrm{~W}=$ $2.1 \mathrm{ml}$. The ANOVA produced a significant retention interval effect $[F(1,31)=21, p<.01]$, but the hydration effect $[F(1,31)=2.4, p>.05]$ and the interaction effect $[F(1,31)=1.9, p>.05]$ were not significant. The 


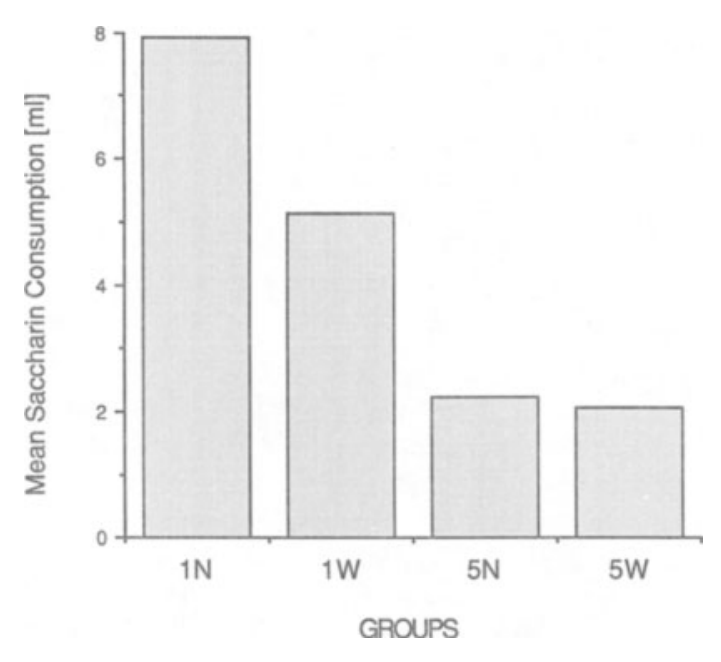

Figure 2. Mean saccharin intake in millimeters on Test Day 1 of Groups 1N, 1W, 5N, and 5W. Groups 1N and 1W were tested 1 day after conditioning, and Groups $5 N$ and $5 W$ were tested 5 days after conditioning. Groups $1 \mathrm{~W}$ and $5 \mathrm{~W}$ received $10 \mathrm{ml}$ of fluid $19 \mathrm{~h}$ before testing, and Groups $1 \mathrm{~N}$ and $5 \mathrm{NW}$ did not receive any replacement fluids during the $24 \mathrm{~h}$ period preceding testing.

planned comparisons showed that Groups $5 \mathrm{~W}$ and $5 \mathrm{~N}$ drank significantly less saccharin than did their 1-day counterparts $(p<.05)$.

It is obvious from these results that the retention-interval differences observed between groups tested 1 day or 5 days after conditioning are not due to the absence of replacement fluids during the CTI. Even after the animals at the 1-day interval were given $10 \mathrm{ml}$ of fluid during this interval, their saccharin intakes were still significantly higher than those of comparably treated animals tested after a 5-day retention interval.

\section{GENERAL DISCUSSION}

In Experiment 1, the animals that were tested 1 day following conditioning had significantly weaker saccharin aversions than those tested either 3,5 , or 10 days after conditioning. Although previous research has determined that the increased drinking at the 1-day interval is not solely due to the aftereffects of illness (see Batsell \& Best, 1992b, Experiment 1 ), the possibility that the retention-interval effect could be due to the absence of replacement fluids during the CTI was examined in Experiment 2. The results of this experiment showed that the differences between the 1-day and 5-day groups were not eliminated by pro- viding replacement fluids during the $24 \mathrm{~h}$ preceding testing. As a result, it appears that taste aversions are significantly weaker if they are tested within $24 \mathrm{~h}$ or conditioning, and this effect is not due to the aftereffects of illness, differential hydration, or the absence of replacement fluids. However, testing is delayed until $\mathbf{3}$ days after conditioning, strong taste aversions are observed.

Various explanations can be posited to account for the retention-interval differences. One interpretation of this phenomenon has centered on the contribution of retrieval competition at shorter retention intervals (Batsell \& Best, 1992b). In this retrieval-competition account, a primary association forms between the taste and illness while a secondary association forms between the environment and illness. When testing occurs at short retention intervals, the environment-illness association will compete with the retrieval of the taste-illness association, and weak taste aversions will be observed. However, as exposure to the conditioning environment increases, the retrieval competition will decrease and stronger taste aversions will be recorded. However, an alternative nonassociative explanation cannot be discounted. It is possible that some aspect of the disruptive conditioning procedure may dishabituate the familiar conditioning environment for a short period following conditioning, thus interfering with the taste aversion. This account is consistent with work demonstrating that a novel conditioning episode can dishabituate a highly familiar context (Mitchell, Kirschbaum, \& Perry, 1975). If true, this contextual dishabituation may be expected to interfere with the expression of the taste aversion at short (e.g., 1-day) CTIs.

\section{REFERENCES}

BATSELl, W. R., JR., \& Best, M. R. (1992a). One bottle too many? Method of testing determines the detection of overshadowing and retention interval effects. Manuscript submitted for publication.

BAtSell, W. R., JR., \& BeST, M. R. (1992b). Variations in the retention of taste aversions: Evidence for retrieval competition. Animal Learning \& Behavior, 20, 146-159.

Biederman, G. B., Milgram, N. W., Heighington, G. A., StockMAN, S. M., \& O'NeILl, W. (1974). Memory of conditioned food aversion follows a U-shape function in rats. Quarterly Journal of Experimental Psychology, 26, 610-615.

Dragoin, W., Hughes, G., Devine, M., \& Bentley, J. (1973). Longterm retention of conditioned taste aversions: Effects of gustatory interference. Psychological Reports, 33, 511-514.

Kraemer, P. J., Lariviere, N. A., \& Spear, N. E. (1988). Expression of a taste aversion conditioned with an odor-taste compound: Overshadowing is relatively weak in weanlings and decreases over a retention interval in adults. Animal Learning \& Behavior, 16, 164-168.

Miller, J. S., Jagielo, J. A., \& Spear, N. E. (1990). Changes in the retrievability of associations to elements of the compound CS determine the expression of overshadowing. Animal Learning \& Behavior, 18, 157-161.

Mitchell, D., Kirschbaum, E. H., \& Perry, R. L. (1975). Effects of neophobia and habituation on the poison-induced avoidance of exteroceptive stimuli in the rat. Journal of Experimental Psychology: Animal Behavior Processes, 1, 47-55.

(Manuscript received May 19, 1992.) 